\title{
Evaluation of liposomal B12 supplementation in a case series study
}

\author{
Ilias Katsogiannis ${ }^{1,2 *}$, Nikolaos Fikioris ${ }^{1}$, Christos Kontogiorgis ${ }^{2}$ and Theodoros Constantinides ${ }^{2}$ \\ ${ }^{1}$ In Touch Health, 11 Merlin, Athens, Greece \\ ${ }^{2}$ Laboratory of Hygiene and Environmental Protection, Department of Medicine, Democritus University of Thrace, 68100, Alexandroupolis, Greece
}

\begin{abstract}
Vitamin B12 deficiency is a very common problem among people of all ages and ethnicities that may cause some serious health problems if left untreated. Traditionally intramuscular injection of B12 was the most common way of treatment, although in recent years a lot of studies have shown that oral supplementation is also effective. Liposomal vitamin B12 has ideal physicochemical characteristics (i.e. size around 450nm and positive surface charge). Namely, we evaluated how does liposomal supplementation affect B12 levels in participants of this study. For this reason, we organized a case series study. The aim of this investigation is to measure the effect of liposomal B12 supplementation in the bloodstream and to evaluate the reproducibility of this effect regardless of lifestyle choices, medication and basic biometric differences between people taking the supplement. We contacted a case series study in a sample of 53 people above 50 years old with a baseline of B12 below $225 \mu \mathrm{g} / \mathrm{ml}$ and we measured their B12 levels 1 week after the treatment start, 1 month after treatment and 2 months after treatment with liposomal B12 supplement sublingually administered 3 times per day providing a total of $1000 \mu \mathrm{g}$ of methylcobalamin daily. Liposomal B12 supplementation was found effective in a very short period of time, which is very beneficial for patients. Vitamin B12 levels has been significantly increased by a median of $54.68 \%$ in the first week of treatment, $105.51 \%$ in the first month and $270 \%$ after two months of treatment. B12 levels increase was found not to be relevant to demographic, biometric, medical treatment and lifestyle factors. Further studies may also be useful to evaluate whether liposomal B12 supplements are superior to conventional supplements and what their possible role in the treatment of patients with B12 deficiency is.
\end{abstract}

\section{Introduction}

Vitamin B12 is synthesized only by certain bacteria and archaea, but not by plants. The synthesized vitamin B12 is transferred and accumulates in animal tissues, which can occur in certain plant and mushroom species through microbial interaction [1-5]. The usual dietary sources of vitamin B12 are animal-source based foods, including meat, milk, eggs, fish, and shellfish, although a few plant-based foods such as certain types of dried lavers (nori) and mushrooms contain substantial and considerable amounts of vitamin B12, respectively. Vitamin B12 is required for the proper function and development of the brain, nerves, blood cells, and many other parts of the body [1-5]. Vitamin B12 deficiency is a common but under-recognized condition which can present with non-specific clinical features and in severe cases with neurological or haematological abnormalities [1-5].

According to Couderc, et al. [6]oral cobalamin supplementation was used in their study with a significant increase in vitamin B12 levels. An oral cobalamin regimen is proposed for elderly patients with cobalamin deficiency but with no severe neurological signs. Pernicious anemia, also known as vitamin B12 deficiency, is defined by two factors that are detected during blood tests and it occurs, when a person lacks the intrinsic agent and cannot absorb B12 [6]. It is the most common cause of malignant anemia and is defined as an autoimmune reaction that attacks and destroys those cells of the stomach that produce the endogenous factor.

Immature, abnormally large red blood cells are fragile megaloblastic erythrocytes which are very inefficient for oxygen transport and white blood cells that are made up of abnormal nuclei. Early symptoms of vitamin B12 deficiency include weakness, fatigue, pale skin, paleness, constipation or diarrhea, loss of appetite, weight loss, indigestion, fragile nails, dark circles, changes in behavior, rapid heartbeat, disorder of reflexes, muscle weakness, neuropathic pain, loss of vision, reduction of cognitive capacity, changes in memory, depression and confusion [6-10]. The absorption of vitamin B12 is a complex process, subject to various problems, in many places. Any deficiencies of pepsin, hydrochloric acid, R-protein, pancreatic enzymes, endogenous factor, calcium receptors and cells can all lead to B12 deficiency through blocked absorption.

Once found in the bloodstream, proteins bind with B12 and transport it to the cells. Within the cells, the enzymes release B12 from the protein complex and convert it into the two forms of the coenzyme, methylcobalamin and adenosylcobalamin $[3,4,10]$. In general, very high levels of B12 are required to cope with the lack of endogenous factor. Nowadays, doctors prescribe injections or oral supplements in even larger doses and treatment is lifelong. Vitamin B12 contributes to the normal function of metabolic processes aimed towards energy production, the process of cell division, red blood cells formation, normal homocysteine metabolism, normal psychological function, normal functioning of the nervous and immune system, and can reduce fatigue and tiredness symptoms [1-4].

${ }^{\star}$ Correspondence to: Ilias Katsogiannis, In Touch Health, 11 Merlin, Athens, Greece and Laboratory of Hygiene and Environmental Protection, Department of Medicine, Democritus University of Thrace, 68100, Alexandroupolis, Greece, E-mail: ilias.kat1@gmail.com

Key words: vitamin B12, liposomes, case series study, sublingual administration

Received: October 15, 2018; Accepted: October 29, 2018; Published: October 31, 2018 
Vitamin B12 is a dietary supplement that contains the most potent form of vitamin B12 as methylcobalamin. Liposomal vitamin B12 is administered sublingually. Liposomes are biocompatible and biodegradable delivery systems that can increase the absorption and the bioavailability of the encapsulated vitamin. Liposomes are closed spherical-like vehicles consisting of an aqueous core surrounded by one or more concentrically arranged bilayer membranes. Additional advantages of using liposomes as vesicles/ drug delivery systems include their ability to encapsulate hydrophilic molecules (i.e. vitamin C) within the aqueous cavity and solubilize lipophilic compounds within the lipid bilayer [11,12].

The distribution of a liposome depends on its physicochemical properties. Factors increasing particle uptake have been extensively described in the literature, including size, lamellarity, size distribution and surface charge. Liposomal vitamin B12 has ideal physicochemical characteristics (i.e. size around $450 \mathrm{~nm}$ and positive surface charge). Liposomes are complex of phosphatidylcholines (from non-genetically modified sunflower lecithin vegetable oil) with glycerin. The specials physicochemical characteristics of liposomal vitamin B12 and their behavior in human body have been already published in the literature $[11,12]$.

The aim of this study is to measure the effect of liposomal B12 supplementation in the bloodstream and evaluate the reproducibility of this effect regardless of lifestyle choices, medication and basic biometric differences between people taking the supplement. Furthermore, we evaluated how fast does liposomal supplementation affect B12 levels in blood plasma, since this might make a big difference to patients with neurological or other symptoms from B12 deficiency. For this reason, we organized a case series study. To the best of the authors' knowledge this type of case series study appears for the first time in the literature. The outcomes of this investigation could be a road map for design and develop new and innovative food supplements using liposomal technology with added value for the patients and health professionals.

\section{Methods}

\section{Study design and population}

We conducted a case series study with a simple random sampling method from a population of people visiting doctor's office, above the age of 50, non-vegetarians, coming from various areas of Greece and the base line of B12 level was below $225 \mathrm{pg} / \mathrm{ml}$. Exclusion criteria: from this study patients with active cancer were excluded as well as patients that the severity of their symptoms is such that need referral to a hospital as soon as possible. Patients with severe mental disorders were also excluded. Questionnaire has been given to patients by the physician regarding lifestyle choices (smoking, alcohol consumption, food). Basic biometric and demographic characteristics have been monitored (height, weight, age and gender) as well as patient's medical history and current pharmaceutical treatment. (Questionnaire form APPENDIX)

The liposomal B12 supplement was administered to patients three times per day sublingually, which has been evaluated equal to $1000 \mu \mathrm{g}$ of methylcobalamin per day, as indicated in the dossier of the formulation (Notification number of the National Organization for Medicines (EOF): 50525/31.5.2017).

\section{Data source}

We measured B12 levels prior to the therapy and then we measured B12 levels one week after the start of the treatment, as well as one month and two months after the start of the therapy. Doctor's Formulas supplied the Liposomal B12 supplement free of charge. Patients were informed that the data would be used by the company for the purpose of a study and gave written consent by signing a form. All measurements were performed by the COBAS E601 analyzer by ROCHE (SERIES 6000) that applies the quantitative electrochemiluminescence method (ELCIA) because we have found that this equipment is easily accessible in most areas in Greece and we wanted to have some consistency in our measurements, acknowledging that because we could not transfer the samples in one central location so we can use only one analyzer, this was the best possible solution to minimize method discrepancy between different analyzers.

\section{Statistical analysis}

Continuous data are expressed as mean with standard deviation (SD), categorical data are presented as percentiles. Fisher's exact test has been used for the evaluation of the statistical significance of our analysis. We conducted hypothesis testing for B12 levels after two months treatment not being equal with baseline B12 levels (dependent sample hypothesis testing). We also conducted hypothesis testing on B12 levels after two months of treatment being equal in subgroups of participants depending on their lifestyle choices and medication usage (independent samples hypothesis testing). All other statistical analyses were conducted using IBM SPSS Statistics 15 (version 15.0; SPSS, Chicago, IL, USA). A p value of $>0.05$ was considered statistically significant in all tests. Descriptive statistical analysis was performed to the demographic and biometric characteristics of the participants and lifestyle choices. Further analysis on B12 levels at the baseline as well as at several stages of treatment. We opted for using median as to best describe the central tendency of our sample

\section{Results}

In total 53 people participated in the study in a period of approximately 7 months and among them $58.5 \%$ were women and $41.5 \%$ men, respectively. None of the patients complained about any side effects or discomfort related to the treatment (Table 1).

Between men and women participants no significant differences were found in basic lifestyle choices and biometrics and also baseline B12 levels. The mean of the age of the participants was approximately 64 years. Specifically, for women the mean age was 62.5 years and for men 64.5 years approximately. The mean BMI value in our sample was 26.5 and the mean value of the Baseline B12 (before treatment) in our sample was $184.03 \mathrm{pg} / \mathrm{ml}$. In the male group the mean BMI was 27.30 and for female group was 26.08 both just above the normal range. Among the participants $58.5 \%$ did not smoke, while the $41.5 \%$ were smokers and the average number of cigarettes per day in our sample is ten. In the female group $35.5 \%$ of the participants were smoking an average of approximately 6 cigarettes per day whereas in the male group $50 \%$ of the participants were smoking an average of approximately 15 cigarettes per day. $19.4 \%$ of the women participants were on metformin for diabetes treatment and $36.7 \%$ of men were on the same treatment. It was found in our sample that $43.4 \%$ of the participants stated that they never consume alcohol and $39.6 \%$ stated that they rarely consume alcohol (once or twice per month) and $13.2 \%$ stated that they regularly consumed alcohol (several times per week). The $3.8 \%$ gave no answer in the alcohol consumption question. Because alcoholism is a taboo subject for many people we avoided trying to get more specific about the participants drinking habits but rather try to have a general idea in case we did get some results that could not be explained easily by other parameters. Regarding alcohol consumption the 2 groups had significantly different drinking habits with men appearing to drink on 
Table 1. General characteristics of case series participants

\begin{tabular}{|c|c|}
\hline Total numbers of preliminary participants & 56 \\
\hline Total number of actual participants & 53 \\
\hline \multicolumn{2}{|l|}{ Gender (\%) } \\
\hline Male & $22(41.5 \%)$ \\
\hline Female & $31(58.5 \%)$ \\
\hline Age (mean \pm SD) $\quad$ (years) & $63.42 \pm 10.66$ \\
\hline Age of males (mean \pm SD) $\quad$ (years) & $64.36 \pm 8.11$ \\
\hline Age of females (mean \pm SD) (years) & $62.74 \pm 12.24$ \\
\hline BMI $($ mean \pm SD) & $26.57 \pm 5.92$ \\
\hline BMI of males (mean \pm SD) & $27.30 \pm 6.91$ \\
\hline BMI of females $($ mean \pm SD) & $26.08 \pm 5.21$ \\
\hline \multicolumn{2}{|l|}{ Smoking habits } \\
\hline Smokers (sample) & $22(41.5 \%)$ \\
\hline Non-Smokers(sample) & $31(58.5 \%)$ \\
\hline Smokers (male) & $11(50 \%)$ \\
\hline Non-smokers (male) & $11(50 \%)$ \\
\hline Smokers (female) & $11(35.5 \%)$ \\
\hline Non-smokers(female ) & $20(64.5 \%)$ \\
\hline Number of cigarettes (sample ) (mean $\pm \mathrm{SD})$ & $9.94 \pm 16.01$ \\
\hline Number of cigarettes (male ) (mean \pm SD) & $15.43 \pm 18.94$ \\
\hline Number of cigarettes (female $)($ mean \pm SD) & $6.23 \pm 12.70$ \\
\hline \multicolumn{2}{|l|}{ Alcohol use } \\
\hline Never & $23(45.1 \%)$ \\
\hline Rare( once per month ) & $21(41.2 \%)$ \\
\hline Often(more than twice a week ) & $7(13.7 \%)$ \\
\hline Never (male) & $8(36.4 \%)$ \\
\hline Rare( once per month ) (male ) & $8(34.6 \%)$ \\
\hline Often(more than twice a week ) (male ) & $6(27.3 \%)$ \\
\hline Never (female ) & $15(48.4 \%)$ \\
\hline Rare( once per month ) (female ) & $13(41.9 \%)$ \\
\hline Often(more than twice a week) (female) & $1(3.2 \%)$ \\
\hline \multicolumn{2}{|l|}{ Metformin groups } \\
\hline Metformin users & $14(26.4 \%)$ \\
\hline Non metformin users & $39(73.6 \%)$ \\
\hline Metformin users(male ) & $8(36.4 \%)$ \\
\hline Non metformin users (male ) & $14(63.6 \%)$ \\
\hline Metformin users (female) & $6(14.94 \%)$ \\
\hline Non metformin users (female ) & $25(80.6 \%)$ \\
\hline
\end{tabular}

a more regular base $(27.3 \%$ answered that they drink several times per week) than women $(3.2 \%$ women answered that they drink several times per week).

In our sample $73.6 \%$ of participants did not use metformin as a medicine of choice for diabetes type 2 and $26.4 \%$ were treated with metformin. Metformin is of particular interest to this study because it's one of the most commonly prescribed medication for diabetes type 2 and also one of the medicines that affect levels of B12 [13]. Furthermore, a study among diabetics treated with metformin comparing sublingual and intramuscular administration of B12 was found in the literature so we had the opportunity to evaluate if there is a significant difference between conventional sublingual dosage forms and liposomal sublingual B12 supplements [14]. It was not specified by the doctors the daily metformin dosage and, thus we cannot correlate dosage of the medication with its effect on supplementation with liposomal B12. However, the statistical analysis that follows, shows no difference on the two months B12 levels in the metformin group vs. the no metformin group.

The baseline of B12 was not significantly different between men and women in our study $(182,18 \mu \mathrm{g} / \mathrm{ml} \pm 33.04$ female vs $185.84 \mu \mathrm{g} / \mathrm{ml} \pm$ 36.59 male, respectively), (Table 2 ).
In, the first week of treatment with liposomal B12 sublingually administered three times per day (1000 $\mu \mathrm{g}$ in total), an increase in B12 levels of $54.68 \%$ or $93.6 \mathrm{pg} / \mathrm{ml}$ was found and the median was measured at $281 \mathrm{pg} / \mathrm{ml}$. After one month of treatment with liposomal B12 we recorded a raise of $105.51 \%$ or $191 \mu \mathrm{g} / \mathrm{ml}$, leading the median of B12 after one-month treatment at $362 \mathrm{pg} / \mathrm{ml}$. At the end of the second month of the treatment, we had approximately $270 \%$ raise of $\mathrm{B} 12$ or $314 \mu \mathrm{g} / \mathrm{ml}$ that brought our median of B12 at $480 \mu \mathrm{g} / \mathrm{ml}$. Test of normality revealed that the distribution was not normal $(\mathrm{p}=0.047)$ so we prefer the median to best describe the central tendency. We runned a wilcoxon signed ranks test and we found that the medians of B12 levels before treatment and after two months of treatment are not equal ( $\mathrm{p}=0$, reject Ho) (Table 2$)$.

Further statistical analysis of the sample showed that if we grouped participants accordingly no significant change occurred in the two groups. Specifically, for people taking metformin, normality test showed that both samples follow normal distribution $(\mathrm{p}=0.325)$ for people not taking metformin and $\mathrm{p}=0.126$ for people taking metformin) and thus a t-test for independent samples could be performed. It was revealed that variances were equal $(\mathrm{p}=0.209)$ and there are no significant differences in the mean of $\mathrm{B} 12$ levels after 2 months of treatment $(\mathrm{p}=0.507)$. Likewise, statistical analysis for smokers revealed that the B12 levels in both samples (smokers and nonsmokers) follow normal distribution ( $p=0.646$ and $p=0.127$ ) and thus T-test for independent samples showed variances are equal $(\mathrm{p}=0.071)$ and the mean B12 levels do not differ significantly in the two groups $(\mathrm{p}=0.166)$ (Table 3$)$.

Finally, we compared mean B12 levels 2 months after treatment for people that answered that never drink alcohol with people that answered that rarely drink and drink alcohol often respectively and came to the conclusion that for our sample, alcohol consumption does not play a significant role in the treatment with liposomal B12. Mean B12 levels in nondrinkers, people that drink rarely and people that consume alcohol more than twice per week all follow normal distribution $(\mathrm{p}=0.111$, $\mathrm{p}=0.407 \mathrm{p}=0.404$ respectively). Thus, it was found no significant difference in the mean of $\mathrm{B} 12$ levels between people that never consume alcohol and people that rarely consume alcohol $(\mathrm{p}=0.723)$ and people that never consume alcohol and people that often consume alcohol $(\mathrm{p}=0.786)$ (Table 3$)$.

Table 2. Median measurements of B12 levels in volunteers plasma

\begin{tabular}{|l|c|c|c|}
\hline & $\begin{array}{c}\text { B12 plasma levels } \\
(\boldsymbol{\mu g} / \mathbf{m l})\end{array}$ & $\begin{array}{c}\text { B12 increase } \\
(\boldsymbol{\mu g} / \mathbf{m l})\end{array}$ & $\begin{array}{c}\text { B12 increase } \\
(\text { percentage })\end{array}$ \\
\hline baseline & $183.71 \pm 34.27$ & - & - \\
\hline 1 week & $281 \pm 82.59$ & $93.60 \pm 62.73$ & $54.69 \% \pm 30.28$ \\
\hline 1 month & $362 \pm 96.6$ & $191 \pm 88.54$ & $105.51 \% \pm 51.20$ \\
\hline 2 months & $480 \pm 104.75$ & $314 \pm 103.15$ & $269.66 \% \pm 72.55$ \\
\hline
\end{tabular}

Table 3. Comparative table of B12 medians after 2 months of treatment in study subgroups

\begin{tabular}{|l|c|c|c|}
\hline \multicolumn{1}{|c|}{$\begin{array}{l}\text { Median B12 levels } \\
\text { 2 months after treatment }\end{array}$} & $502.50 \pm 80.04$ & \multicolumn{2}{|c|}{ Non-smokers } \\
\hline & \multicolumn{2}{|c|}{ Metformin } & \multicolumn{2}{|c|}{ No Metformin } \\
\hline $\begin{array}{l}\text { Median B12 levels } \\
\text { 2 months after treatment }\end{array}$ & $507.50 \pm 80.08$ & \multicolumn{2}{|c|}{$475 \pm 112.65$} \\
\hline $\begin{array}{l}\text { Alcohol Consumption } \\
\text { Median B12 levels } \\
\text { 2 months after treatment }\end{array}$ & Never & Rarely & Often \\
\hline
\end{tabular}




\section{Discussion}

Our case series study found liposomal B12 supplementation in people over 50 years old with a baseline B12 levels beyond $225 \mu \mathrm{g} / \mathrm{ml}$, to be successful regardless of lifestyle choices. It is the first time that a case series study is presented on B12 supplements evaluating the potential role of demographic, biometric and lifestyle factors in its efficiency. In our case series study, we have found no significant difference in B12 levels in people taking metformin and people not taking metformin and in that sense it seems that liposomal B12 is superior for patients on metformin. However, Parry Strong, et al. [14] presented a study, where 34 people participated with diabetes type 2 on metformin and it was found that higher metformin dose was associated with lower serum $\mathrm{B} 12$ at 3 months, and the mean B12 levels after 3 months of oral B12 supplementation was $372.1(103.3) \mu \gamma \mathrm{l} / \mathrm{ml}$.

In our study, it was found that B12 levels have been significantly increased in a short period of time with a noninvasive way that puts people participating in this study in the normal range of B12. In addition, it was found that after two months treatment that blood plasma B12 levels were found $480 \mu \mathrm{g} / \mathrm{ml} \pm 104.75$, which presented significant differences from those presented in previous literature. For example, Kuzminski et al. [15] in a clinical trial in 1998 comparing oral administration of $1000 \mu \mathrm{g}$ per day of vitamin B12 and intramuscular administration of the same dosage in two separate groups concluded that mean B12 levels after 4 months of treatment was 1005 pmol./lt in the tablet group which is considerably higher than other studies [15]. Castelli et al. [16] conducted a comparison study in 2011 between oral and injectable B12 treatment in two separate groups and it was found that injectable B12 achieved higher plasma concentration in 2 months' time vs. orally administered supplement ( 452.5 oral group vs. 714.6 injectable group, respectively) [16]. It has to be mentioned that severe differences in blood plasma measurements of B12 have been observed among the most of the already presented references.

According to our first step analysis it is well documented that liposomal B12 supplementation is very effective presenting a noninvasive way to treat $\mathrm{B} 12$ deficiency in a very short period, which seems to be beneficial for patients. This kind of pharmaceutical form (sublingual spray) is quite useful for people with swallowing difficulties (elderly people with late stage Parkinson's disease or Alzheimer's for example) who are usually malnutrition because of their inability to be fed properly and to actively take conventional supplementation orally [17]. However further research is needed to prove this point as these people have specific needs.

\section{Conclusions}

In this first case series study on liposomal B12 supplementation it was found that this new formulation presents significant effectiveness in a very short period for the patients. Further studies may also be useful to signify the potential role of liposomal supplements vs. conventional food supplements orally administered. This is a first step in presenting new generation of liposomal B12 supplementation and their possible role in the treatment of patients with B12 deficiency, which was found not be relevant to biometric and lifestyle factors.

\section{Conflict of interest}

There is no conflict of interest.

\section{References}

1. Gille D, Schmid A (2015) Vitamin B12 in meat and dairy products. Nutr Rev 73: 106115. [Crossref]
2. Watanabe F, Bito T (2018) Vitamin B12 sources and microbial interactions. Exp Biol Med (Maywood) 243: 148-158. [Crossref]

3. Watanabe F, Yabuta Y, Tanioka Y, Bito T (2013) Biologically active vitamin B12 compounds in food for preventing deficiency among vegetarians and elderly subjects. $J$ Agric Food Chem 61: 6769-6775. [Crossref]

4. Shipton MJ, Thachil J (2015) Vitamin B12 deficiency -A $21^{\text {st }}$ century perspective. Clin Med (Lond) 15: 145-150.

5. Dharmarajan TS, Adiga GU, Norkus EP (2003) Vitamin B12 efficiency. Recognizing subtle symptom in older adults. Geriatrics 58: 37-38. [Crossref]

6. Couderc AL, Camalet J, Schneider S, Turpon JM, Bereder I, et al. (2015) Cobalamin deficiency in the elderly: etiology and management: a study of 125 patients in a geriatric hospital. J Nutr Health Aging 19: 234-239. [Crossref]

7. Kennedi DO (2016) B Vitamins and the brain: mechanisms, dose and efficacy-A review. Nutrients 8: 68. [Crossref]

8. O’Leary F, Samman S (2010) Vitamin B12 in health and disease. Nutrients 2: 299-316. [Crossref]

9. Gherasm C, Lofgren M, Banerjee R (2013) Navigating the B(12) road: assimilation, delivery and disorders of cobalamin. J Biol Chem 288: 13186-13193. [Crossref]

10. Chan CQ, Low LL, Lee KH (2016) Oral Vitamin B12 replacement for the treatment of pernicious anemia. Front Med (Lausanne) 3: 38. [Crossref]

11. Pippa N, Fikioris N, Demetzos C (2017) Evaluation of the physicochemical characteristics of liposomal formulations of Doctor's Formulas' Food supplements. Adv Sci, Eng Med 9: 148-154.

12. Pippa N, Fikioris N, Demetzos C (2017) Physicochemical characteristics of liposomal formulations of Doctor's Formulas' Food supplements in biorelevant dispersion media. Adv Sci, Eng Med 9: 648-652.

13. Reinstatles L, Ping Y, Williamson RS, Garn JV, Oakley GP (2012). Association of Biochemical B12 Deficiency with metformin therapy and vitamin B12 supplements. The National health and Nutrition Examination survey, 1999-2006. Diabetes Care 35: 327-333. [Crossref]

14. Parry-Strong A, Langdane F, Haeusler S, Weatherall M, Krebs J (2016) Sublingual vitamin B12 compared to intramuscular injection in patients with type 2 diabetes treated with metformin: a randomized trial. $N Z$ Med $J$ 129: 67-75. [Crossref]

15. Kuzminski AM, Del Giacco EJ, Allen RH, Stabler SP, Lindenbaum J (1998) Effective treatment of cobalamin deficiency with oral cobalamin. Blood 92: 1191-1198. [Crossref]

16. Castelli MC, Friedman K, Sherry J, Brazzillo K, Genoble L, et al. (2011) Comparing the efficacy and tolerability of a new daily oral vitamin B12 formulation and intermittent intramuscular vitamin B12 in normalizing low cobalamin levels: a randomized, openlabel, parallel-group study. Clin Ther 33: 358-371. [Crossref]

17. Nausieda PA, Pfeiffer RF, Tagliati M, Kastenholz KV, DeRoche C, et al. (2005). A multicenter, open-label, sequential study comparing preferences for carbidopalevodopa orally disintegrating tablets and conventional tablets in subjects with Parkinson's disease. Clin Ther 27: 58-63. [Crossref]

Copyright: (C2018 Katsogiannis I. This is an open-access article distributed under the terms of the Creative Commons Attribution License, which permits unrestricted use, distribution, and reproduction in any medium, provided the original author and source are credited. 